\title{
Using innovative interactive technologies for forming linguistic competence in global mining education
}

\author{
Galina Chistyakova ${ }^{1, *}$, Evgeniya Bondareva $^{1}$, Kseniya Demidenko ${ }^{1}$, Ekaterina \\ Podgornaya ${ }^{1}$, and Oksana Kadnikova ${ }^{1}$ \\ ${ }^{1}$ Plekhanov Russian University of Economics, Kemerovo Branch, Department of Humanities, \\ 650992 Kemerovo, 39 Kuznetsky Av., Russia
}

\begin{abstract}
Globalization of mining education imposes new requirements for mining engineer competence. Nowadays linguistic competence is one of the most demanded. It guarantees technical university graduates the possibility of global employment, on the one hand, and the chance of getting cutting edge education in leading training centers of the world, on the other hand. Distance education is actively developing all over the world and is widely used in technical colleges and universities, as well. Interactive method that involves active engagement of students appears to be of the greatest interest due to introduction of modern information and communication technologies for distance learning. The paper presents step-by-step implementation of several interactive technologies (jigsaw, case study, brainstorming, and role-play) that can be used in distance education in the process of teaching subjects in foreign languages with the help of information and communication technologies. In response to the changes in the conditions of educational process, the implementation of the methods has been transformed to a combination of traditional (in-class) and distance (online) learning.
\end{abstract}

\section{Introduction}

It is generally accepted that distance learning is an integral part of modern education alongside the traditional in-class studying. A number of authors in their research papers consider innovative structures and components of distance learning in education [1]. Mining engineers training is no exception with the world leading higher technical schools and universities offering distance-learning services. The main language of educational programs is English, which requires students' knowledge of not only general, but also professional vocabulary.

The tendency of gradual conversion of global mining education to the distance learning format is quite understandable if one looks at last decades' intensive development of technical means. Functioning of XXI Century University, in our opinion, is not possible without new resources, including modern information and communication technologies that

\footnotetext{
*Corresponding author: galvik06@mail.ru
} 
enable to increase the number of participants in educational process. The development of distance learning technologies ensures the possibility of providing educational services without being tied to a specific geographical location (Open and Distance Learning).

\section{Material and method}

Even though distance learning technologies in the sphere of mining engineers training are innovative, they have proved to affect the process positively. Thus, positive relation between students' usage of information technologies for educational purposes and their involvement in learning and interaction with lecturers has been acknowledged [2, 3, 4]. Another study has shown that the use of Twitter for educational purposes has a positive effect on students' learning interest and the average semester grades [5]. Some authors analyze the effectiveness of distance learning basing on students' own evaluation of the educational process [6,7] and evaluation of students by their teachers [8]. A group of scientists have compared traditional (off-line), on-line and mixed forms of education and have proved that educational results in groups with mixed education methods are the highest [9].

In the context of implementing distance learning technologies into the training of mining engineers, the process of educational design (specifically targeted planning of training courses) should be adjusted towards finding some learning forms and methods that can encourage students to self-study of foreign languages alongside with university training.

The target mentioned can be reached by applying e-learning and distance learning that can be successfully used for forming linguistic competence of future mining engineers. Elearning can be applied in a traditional form (in-class face-to-to-face learning), when students use electronic devices and resources of the university or their own mobile devices as educational tools. Distance learning allows students to acquire knowledge by accessing university virtual educational environment with the help of any computer connected to the Internet.

Educational design of the courses with elements of distance education requires a certain level of professional creativity from the educators teaching courses in foreign languages.

Among the innovative methods of foreign language teaching, the interactive approach appears to be the most promising in terms of distance technologies. It is based on active interaction of students. Teachers act as consultants and coordinators of students' educational and research activities. They step aside while students' work intensifies and dominates the process.

Some research works are dedicated to the importance of the interactive approach in learning using materials and information about real situation in economy in general and in mining industry in particular $[10,11]$. Researchers pay attention to the theoretical description of the method analyze specific industrial technologies [12]; or consider the possibility of using interactive methods when teaching particular subjects concerning mining industry [13]. Evidently, it is of interest to contemplate the usage of the interactive approach in distance education.

New teaching methods, based on using modern information and communication technologies (webinars, interactive multimedia, online learning, etc.), allow developing distant forms that do not involve teacher's direct physical participation in the process. It is impossible to overestimate modern information and communication technologies: they provide access to the sources of information previously unused; significantly increase efficiency of students' independent work; provide completely new opportunities for creativity, identification and demonstration of capabilities, acquiring and consolidating different skills, both of a teacher and a student; allow implementing essentially new forms 
and methods of training (local and global information networks, conference calls, e-mail, elibraries, forums, chats, and others). It is worth mentioning that distance learning technologies can noticeably reduce the level of panic and stress experienced by students when taking tests and exams in traditional forms, increase students' initiative and motivation, as well as their psychological comfort.

Using information and communication technologies in educational process enables to address the following didactic tasks more effectively: forming and improving reading, writing, speaking, and listening skills, as well as extending students' active and passive vocabulary. The authors particularly emphasize that students are provided with an extra opportunity of facing social and cultural environment of foreign languages they study (speech etiquette, verbal behavior, culture issues, traditions of foreign countries, etc.), as well as increasing academic motivation through the use of authentic materials [14]. Undoubtedly, that contributes to forming skills useful for solving professional problems in a foreign language as a means of direct as well as indirect communication.

Both in traditional and distance educational systems, fulfillment of educational goals in disciplines taught in foreign languages depends on the quality of learning materials, facilities of the educational environment, professional skills as well as information and communication competence of teachers. An important role is also attributed to the correct choice of tasks, which demand using information and communication technologies, such as working with e-learning materials, using Internet resources in foreign languages, performing online tests and exercises, etc.

\section{Results and discussion}

When summarizing authors' long-term practice in using innovative methods for teaching foreign languages, it can be stated that it is the interactive approach that demonstrates maximum efficiency in developing linguistic competence in a foreign language through the use of distance technologies.

In terms of distance learning, among interactive teaching techniques the main interest is aroused in technologies and methods to be implemented within two stages: preparation and presentation. It is possible to use distance learning technologies at the preparation stage, when students communicate, for example, by means of Skype-based video conferencing. This technology is used in synchronous distance education which offers an environment closer to the traditional in-class environment, and allows students to establish visual and voice communication with teachers [15]. During video conferences students discuss their tasks, choose the leader of the working group, distribute authorities, produce and edit texts, etc. A set of actions performed at the preparation stage depends on the technology used. Teacher's participation in such video conferences is optional.

This article focuses on step-by-step description of implementing traditional interactive learning technologies applied with the help of innovative information and communication technologies in the course of foreign language teaching. The technologies under consideration are: jigsaw, case study, brainstorming, role-play.

Jigsaw technology was developed by Dr. Elliot Aronson in 1978. Using this technology assumes that students are divided into teams of 4 to 6 people to work with some training material (for example, a text on the section of the subject), which is divided into fragments (logical or semantic units). It is recommended to perform the division into the teams and explain the task during in-class activity.

During the preparation (distant) stage the following set of tasks is performed:

- each team member examines a part of the material (offline independent out-of-class activity); 
- "experts meeting", when students from different teams who explored the same part of the material meet and exchange information acting as experts in this section (online team out-of-class activity);

- experts return to their teams and share discovered information with other team members. Thus, each expert acts as a "tooth of a saw" (online out-of-class activity).

Each participant of the educational process (each expert) is responsible for the extent to which all members of the team acquire new information. The work of each team member (expert and / or student) is reflected in their final evaluation.

The presentation (traditional) stage, evaluation of the acquired knowledge, is held by the teacher during the in-class work (face-to-face learning). Testing is carried out individually and / or as a team. The choice of a particular task type depends on the level of the linguistic skills of the academic group [16], the type of the material under consideration, time available, etc.

«Case study» technology was first applied in the mid-twentieth century at Harvard Business School. The principles of the technology are as follows: students receive a training case; after considering the task and the problem it poses, which, as a rule, has no unique solution, students are supposed to propose their own decision, based on the acquired knowledge and skills. Applying case-technology during language classes leads to improvement of students' speaking skills as a result of discussing a problem under consideration.

The preparation stage of training based on «Case Study» technology consists of two stages: organization and implementation. It is advisable to carry out the organizational work as a traditional offline classroom team activity. At this stage, the teacher explains the task and introduces materials to be examined. The implementation stage (students' detailed acquaintance with the information on the case, task execution, and decision-making) is held in online form (online independent out-of-class work). At the same time, students have access to additional resources that might be required during the preparation.

The final (traditional) stage, presentation of the case solution, is carried out in class (offline team classroom activity). The teacher assesses the level of language skills developed and provides the team with feedback on their performance. Each member's personal contribution to the teamwork is defined by the students themselves.

«Brainstorming» technology is one of the most popular technologies used in foreign language training. It is effective for stimulating students' creativity. Participants are encouraged to propose a great variety of suggestions, including most improbable ones. The discussion of the problem usually lasts from 1 to 5 minutes; afterwards, the most feasible solution of the problem is chosen.

It is generally considered that this technology can be used offline only, since it is necessary to write the ideas down on the board or a piece of paper for the purpose of selecting the best. However, modern information and communication technologies provide a way of not only seeing and hearing one another during the communication process, but also actively interacting with a variety of online graphic editors, available to all the participants simultaneously.

The preparation stage may be carried out in two ways:

1. Offline in-class team activity: the teacher divides the students into teams, appoints the leaders of each team (members of the teams who are responsible for organizing the conference, recording ideas, managing the discussion), and provides them with the tasks for consideration.

2. Online out-of-class teamwork: the teacher organizes the conference, appoints the leaders, and provides the task. This activity is followed by an online discussion in which students choose the best ideas and prepare to defend their point of view in front of other 
teams. The online discussion, during which students select the best ideas and prepare for speaking up for their point of view, concludes the preparation stage.

The presentation (traditional) stage is held as an offline classroom team activity during which the results are presented by the teams. As an additional activity, one idea can be chosen and developed into an independent project (Project technology).

«Role-play» technology is another effective way of forming linguistic competence which makes it possible to introduce foreign language training to the model of mining engineers' future work. During this activity students learn how to deal with problems that they might encounter in their professional activity.

At the preparation stage (offline team in-class activity), the teacher forms teams, explains the tasks for the role-play, and determines the degree of students' creativity freedom. Discussing key positions (distributing roles, determining the course of the game, etc.) and writing an open-ended script takes place in a distant form (online team out-ofclass activity). The teacher reviews the script via e-mail.

The presentation (traditional) stage is carried out in the classroom (offline team in-class activity) in the form of presenting the game for the teacher and other academic groups. At the stage of discussing the results of the activity (offline team in-class work) students have an additional opportunity to communicate in a foreign language.

Questioning students reveals that they have been using information and communication technologies for homework preparation without extra motivation from their teachers. This fact indicates that it is university teachers, not students, who should reconsider their position regarding the use of distance learning technologies in teaching foreign languages. Success of students' remote communication depends largely on teachers' motivation and competence in implementing information and communication technologies in educational process.

\section{Recommendations}

Developing forms and methods of distance learning as a part of designing and implementing professional training programs still raises a number of issues. At present, strengthening the position of distance learning with the help of information and communication technologies in the process of teaching foreign languages requires the following:

- conducting regular surveys of students on the issues of training with elements of distance learning technologies;

- working out guidelines on using distance learning technologies in teaching;

- holding seminars for university teachers devoted to distance learning technologies in teaching;

- including in educational content tasks that require using information and communication technologies;

- developing a mechanism of monitoring students' out-of-class activities with the use of distance learning technologies.

\section{Conclusions}

Like any living organism, educational process can develop and improve only within the terms and the conditions the society lives in. Modern society cannot be imagined without information and communication technologies extensively used in education, including distance learning. The next step in developing distance education is transforming methods used in traditional education into new forms of teaching that can be implemented with the 
use of information and communication technologies. Interactive methods should be particularly valued among them, as they are positively perceived by students and demonstrate high effectiveness in forming linguistic competences of graduates.

\section{References}

1. M. Leontev, MATEC Web of Conferences 7307005 7, 07005 (2016)

2. T.F.N. Laird, G.D. Kuh, Research in Higher Education, 46(2), 211 (2005)

3. T. Krasnova, A. Popova, SHS Web of Conferences 28, 01059 (2016)

4. S. Alumu, P. Thiagarajan, Indian Journal of Science and Technology, 9(6) (2016)

5. R. Junco, G. Heiberger, E. Loken, J. of Computer Assisted Learning, 27(2), 119 (2011)

6. I. Rudaleva, I. Kabasheva, E. Kovaleva, SHS Web of Conferences 26, 01128 (2016)

7. M. Kuimova, A. Kiyanitsyna, A. Truntyagin, SHS Web of Conferences 28, 01129 (2016)

8. A.Y. Awadh, Al-Qahtani, E. Higgins, Journal of Computer Assisted Learning, 29(3), $220(2013)$

9. L.-T. Lee, J. Hung, Human-centric Computing and Information Sciences, 5, 15 (2015)

10. M.A. Tyulenev, Y.V. Lesin, Mining 2014: Taishan academic forum - Project on mine disaster prevention and control, 441 (Atlantis Press, Paris, 2014)

11. Yu.V. Lesin, S.Yu. Luk'yanova, M.A. Tyulenev, J. Min. Sci., 46, 78 (2010)

12. S. Zhironkin, M. Gasanov, K. Kolotov, EpSBS, XIX, 761 (2017)

13. M.A. Tyulenev, T.N. Gvozdkova, S.A. Zhironkin, E.A. Garina, Geotech. Geol. Eng., 35, 203 (2017)

14. N.V. Ivleva, E.V. Fibikh, IOP Conf. Series: Materials Science and Engineering 70, 012012 (2015)

15. S. Ghazal, Z. Samsudin, H. Aldowah, Indian Journal of Science and Technology, 8(30) (2015)

16. A.A. Khoreshok, S.A. Zhironkin, M.A. Tyulenev, G.A. Barysheva, V.Y. Blumenstein, M.C. Hellmer, S.V. Potyagailov, IOP Conf. Ser.: Mater. Sci. Eng., 142, 012122 (2016) 